\title{
A HIGH-SPEED TREE-BASED 64-BIT CMOS BINARY COMPARATOR
}

\author{
Anjuli $^{1}$, Satyajit Anand ${ }^{2}$ \\ ${ }^{1}$ M.Tech.VLSI Design, E\&CE Deptt., FET-MITS, Lakshmangarh, Sikar, Rajasthan (India), anjuli_222@yahoo.com \\ ${ }^{2}$ Asst. Prof., E\&CE Deptt., FET-MITS, Lakshmangarh, Sikar, Rajasthan (India), satyajitanand45@gmail.com
}

\begin{abstract}
A high-speed tree-based 64-bit CMOS binary comparator is proposed in this brief. Comparison is most basic arithmetic operation that determines if one number is greater than, equal to, or less than the other number. Comparator is most fundamental component that performs comparison operation. This brief presents comparison of modified and existing 64-bit binary comparator designs concentrating on delay. Means some modifications are done in existing 64-bit binary comparator design to improve the speed of the circuit. Comparison between modified and existing 64-bit binary comparator designs is calculated by simulation that is performed at 90nm technology in Tanner EDA Tool.
\end{abstract}

Index Terms: Binary comparator, digital arithmetic, high-speed

\section{INTRODUCTION}

In digital system, comparison of two numbers is an arithmetic operation that determines if one number is greater than, equal to, or less than the other number [1]. So comparator is used for this purpose.

Magnitude comparator is a combinational circuit that compares two numbers, $\mathrm{A}$ and $\mathrm{B}$, and determines their relative magnitudes (Figure 1) [1]. The outcome of comparison is specified by three binary variables that indicate whether $A>B$, $\mathrm{A}=\mathrm{B}$, or $\mathrm{A}<\mathrm{B}$.

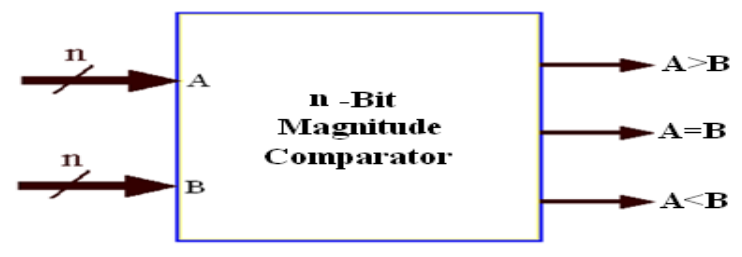

Figure 1. Block Diagram of n-Bit Magnitude Comparator

The circuit, for comparing two n-bit numbers, has 2 n inputs $\&$ $2^{2 n}$ entries in the truth table. For 2-bit numbers, 4-inputs \& 16rows in the truth table, similarly, for 3-bit numbers 6-inputs \& 64-rows in the truth table [1].

The logic style used in logic gates basically influences the speed, size, power dissipation, and the wiring complexity of a circuit. Circuit size depends on the number of transistors and their sizes and on the wiring complexity. The wiring complexity is determined by the number of connections and their lengths. All these characteristics may vary considerably from one logic style to another and thus proper choice of logic style is very important for circuit performance [2].
In order to differentiate all three designs existing and modified, simulations are carried out for power and delay at 1 volt supply voltage (and input voltage) at 90nm technology in Tanner EDA Tool.

\section{64-BIT BINARY COMPARATOR}

64-bit binary comparator compares two numbers each having 64 bits $\left(\mathrm{A}_{63}\right.$ to $\mathrm{A}_{0} \& \mathrm{~B}_{63}$ to $\left.\mathrm{B}_{0}\right)$. For this arrangement truth table has 128 inputs \& $2^{128}$ entries. By using comparator of minimum number of bits, a comparator of maximum number of bits can be design using tree structure logic.

\section{EXISTING 64-BIT BINARY COMPARATOR DESIGN}

64-bit Comparator in reference [3], [4], [5] represents treebased structure which is inspired by fact that $\mathrm{G}$ (generate) and $\mathrm{P}$ (propagate) signal can be defined for binary comparisons, similar to $G$ (generate) and $P$ (propagate) signals for binary additions.

Two number (each having 2-bits: $\mathrm{A}_{1}, \mathrm{~A}_{0} \& \mathrm{~B}_{1}, \mathrm{~B}_{0}$ ) comparison can be realized by:

$$
\begin{aligned}
& \mathrm{B}_{\mathrm{Biz}}=\overline{\mathrm{A}}_{1} \mathrm{~B}_{1}+\left(\overline{\bar{A}_{1} \oplus \mathrm{B}_{1}}\right) \cdot\left(\overline{A_{0}} \mathrm{~B}_{0}\right) \\
& \mathrm{EQ}=\left(\overline{A_{1} \oplus \mathrm{B}_{1}}\right) \cdot\left(\overline{\hat{A}_{0} \oplus \mathrm{B}_{0}}\right)
\end{aligned}
$$

For $\mathrm{A}<\mathrm{B}$, " $\mathrm{B}_{\mathrm{Big}}$, EQ" is " 1,0 ". For $\mathrm{A}=\mathrm{B}$, " $\mathrm{B}_{\mathrm{Big}}, \mathrm{EQ}$ " is " 0,1 ". Hence, for $A>B$, " $B_{B i g}, E Q$ " is " 0,0 ". Where $B_{B i g}$ is defined as output A less than B (A_LT_B). A closer look at equation (1) reveals that it is analogous to the carry signal generated in binary additions. Consider the following carry generation: 


$$
\begin{aligned}
C_{\text {out }} & =A B+(A \oplus B) \cdot C_{\text {in }} \\
& =G+P \cdot C_{\text {in }}
\end{aligned}
$$

Where A \& B are binary inputs, $\mathrm{C}_{\mathrm{in}}$ is carry input, $\mathrm{C}_{\text {out }}$ is carry output, and $\mathrm{G} \& \mathrm{P}$ are generate \& propagate signals, respectively.

After comparing equations (1) \& (3):

$$
\begin{aligned}
& \mathrm{G}_{1}=\overline{\mathrm{A}_{1}} \mathrm{~B}_{1} \\
& \mathrm{EQ}=\left(\overline{A_{1} \oplus \mathrm{B}_{1}}\right) \\
& \mathrm{Cin}=\overline{\mathrm{A}_{0}} \mathrm{~B}_{0}
\end{aligned}
$$

$\mathrm{C}_{\text {in }}$ can be considered as $\mathrm{G}_{0}$. Since for static logic, equation (1) requires tall transistor stack height, hence, an encoding scheme is employed to solve this problem. For this, encoding equation is given as:

$$
\begin{aligned}
& \mathrm{G}_{[i]}=\overline{\mathrm{A}_{[i]}} \mathrm{B}_{[i]} \\
& \mathrm{EQ}_{[i]}=\overline{\mathrm{A}_{[i]}} \oplus \mathrm{B}_{[i]}
\end{aligned}
$$

Where $\mathrm{i}=0 \ldots \ldots \ldots .63$.

Put these two values from equations (7) \& (8) in equations (1) $\&(2)$.

$$
\begin{aligned}
& \mathrm{B}_{\mathrm{Bi}[2 j+1: 2]]}=\mathrm{G}_{[2 j+1]}+\mathrm{EQ}_{[2 j+1]} \cdot \mathrm{G}_{[2]]} \\
& \mathrm{EQ}_{[2 j+1: 2]}=\mathrm{EQ}_{[2 j+1]} \cdot \mathrm{EQ}_{[2]}
\end{aligned}
$$

Where $\mathrm{j}=0 \ldots \ldots \ldots . . .31$.

$\mathrm{G} \& \mathrm{P}$ signals can be further combined to form group $\mathrm{G} \& \mathrm{P}$ signals.

$$
\begin{aligned}
& \mathrm{B}_{\mathrm{Bi}[\mathrm{B}: 0]}=\overline{\mathrm{A}_{3}} \mathrm{~B}_{3}+\left(\overline{\mathrm{A}_{3} \oplus \mathrm{B}_{3}}\right) \cdot \overline{\mathrm{A}_{2}} \mathrm{~B}_{2}+\left(\mathrm{A}_{3} \oplus \mathrm{B}_{3}\right) \cdot\left(\mathrm{A}_{2} \oplus \mathrm{B}_{2}\right) \cdot \mathrm{A}_{1} \mathrm{~B}_{1} \\
& +\overline{\left(A_{3} \oplus B_{3}\right)} \cdot\left(\overline{A_{2} \oplus B_{2}}\right) \cdot\left(\overline{A_{1} \oplus B_{1}}\right) \cdot \overline{A_{0}} B_{0} \\
& =\overline{\mathrm{A}}_{3} \mathrm{~B}_{3}+\left(\overline{\mathrm{A}_{3} \oplus \mathrm{B}_{3}}\right) \cdot\left[\overline{\mathrm{A}}_{2} \mathrm{~B}_{2}+\left(\overline{\mathrm{A}_{2} \oplus \mathrm{B}_{2}}\right) \cdot\left\{\overline{\mathrm{A}}_{1} \mathrm{~B}_{1}\right.\right. \\
& \left.\left.+\left(\overline{A_{1} \oplus B_{1}}\right) \cdot \overline{A_{0}} B_{0}\right\}\right] \\
& =\mathrm{G}_{3}+\mathrm{EQ}_{3} \cdot\left\{\mathrm{G}_{2}+\mathrm{EQ}_{2} \cdot\left(\mathrm{G}_{1}+\mathrm{EQ}_{1} \cdot \mathrm{G}_{0}\right)\right\} \\
& \mathrm{B}_{\mathrm{Biz}[: 0]}=\mathrm{B}_{\mathrm{Biz}[3: 2]}+\mathrm{EQ}_{[\mathrm{B}: 2]} \cdot \mathrm{B}_{\mathrm{Biz}[1: 0]} \\
& \mathrm{EQ}_{[3: 0]}=\mathrm{EQ}_{[3]} \cdot \mathrm{EQ}_{[2]} . \mathrm{EQ}_{[1]} \cdot \mathrm{EQ}_{[0]}
\end{aligned}
$$

Similarly, for 64-bit comparator, $\mathrm{B}_{\mathrm{Big}} \& \mathrm{EQ}$ can be computed as:

$$
\begin{aligned}
& \mathrm{B}_{\mathrm{Biz}[63: 0]}=\mathrm{G}_{63}+\sum_{\mathrm{k}=0}^{62}\left(\mathrm{G}_{\mathrm{k}}, \prod_{\mathrm{m}=\mathrm{k}+1}^{63} \mathrm{EQ}_{\mathrm{m}}\right) \\
& \mathrm{EQ}_{[63: 0]}=\prod_{\mathrm{m}=0}^{63} \mathrm{EQ}_{\mathrm{m}}
\end{aligned}
$$

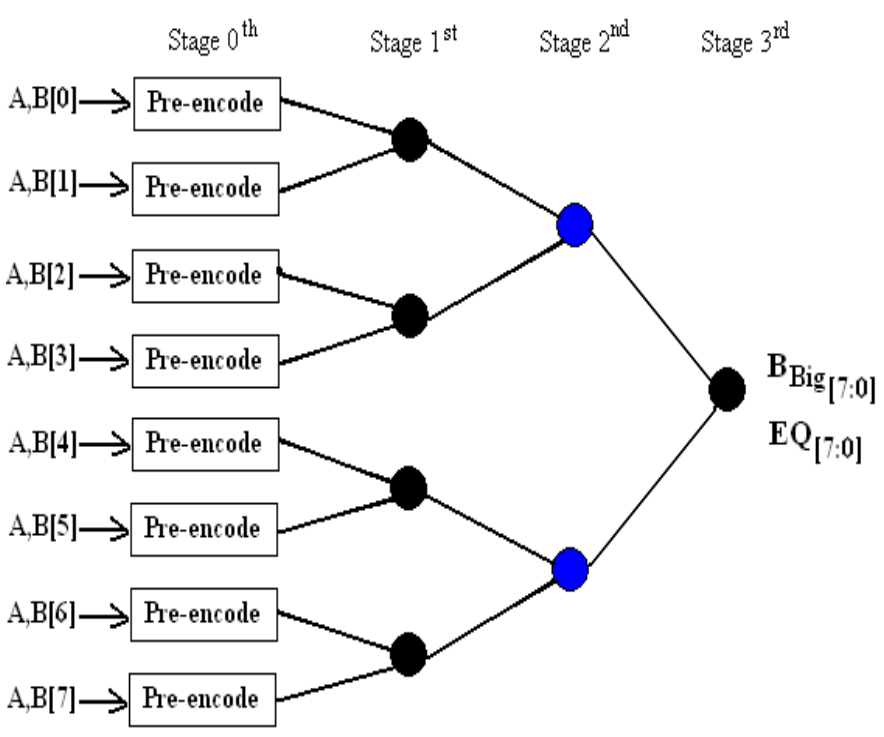

Figure 2 Tree-Diagram of 8-Bit Binary Comparator

Above Figure 2 shows 8-bit version of existing tree-based comparator structure and Figure (3, 4 \& 5$)$ shows corresponding circuit schematics for each logic block of each stage. Pre-encoding circuitry is aimed to minimize the number of transistors. Hence, modified pass transistor logic style is employed to reduce the number of transistors up to 9 (including inverters).

In above 8-bit example circuitry, the first stage comparison circuit implements equations $(9,10)$ for $j=0 \ldots 3$, whereas the second stage generates $\mathrm{B}_{\mathrm{Big}[3: 0]}, \mathrm{B}_{\mathrm{Big}[7: 4]}$ and $\mathrm{EQ}_{[3: 0]}, \mathrm{EQ}_{[7: 4]}$ according to equations $(11 \& 12)$. Finally, $\mathrm{B}_{\mathrm{Big}[7: 0]}$ and $\mathrm{EQ}_{[7: 0]}$ are computed in the third stage according to equations (13 \& 14).

Stage $0^{\text {th }}$ is implemented using modified pass transistor logic style [6], [7] giving output in actual form, Stage $1^{\text {st }}$ is implemented using CMOS logic style giving output in inverse form, Stage $2^{\text {nd }}$ is also implemented using CMOS logic style giving output in actual form.64-bit comparator is here designed by using 7 stages (from $0^{\text {th }}$ to $6^{\text {th }}$ ). In stage $0^{\text {th }}$, modified pass transistor logic style circuitry (as in Figure 3 ) is employed to produce "less than" \& "equal to" outputs. Outputs of stage $0^{\text {th }}$ are act as inputs of stage $1^{\text {st }}$. In stage $1^{\text {st }}$, CMOS circuitry (as in Figure 4) is employed to produce inverse inputs for stage $2^{\text {nd }}$. In stage $2^{\text {nd }}$, again CMOS circuitry (as in Figure 5) is employed to produce actual inputs for stage $3^{\text {rd }}$. Now, according to tree structure given in Figure 2, again circuitry of stage $1^{\text {st }}$ is used for stage $3^{\text {rd }}$. Similarly, for stage $4^{\text {th }}$, circuitry of stage $2^{\text {nd }}$ is employed. For stage $5^{\text {th }}$ circuitry of 
stage $1^{\text {st }}$ is employed. For stage $6^{\text {th }}$ circuitry of stage $2^{\text {nd }}$ is employed. Accordingly schematic of Existing 64-bit binary comparator is drawn and shown in Figure 6. Description of this design is given in tabular form in table I.

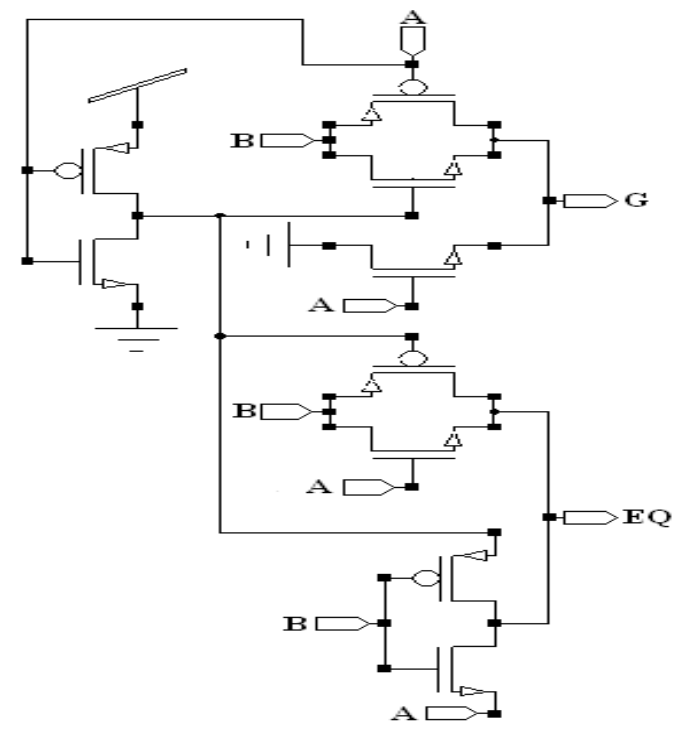

Figure 3. Schematic of Stage $0^{\text {th }}$ of Existing 64-Bit Binary Comparator
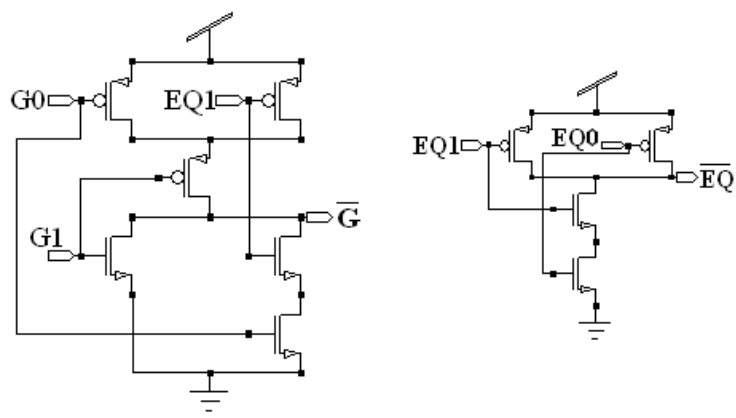

Figure 4 Schematic of Stage $1^{\text {st }}$ of Existing 64-Bit Binary Comparator
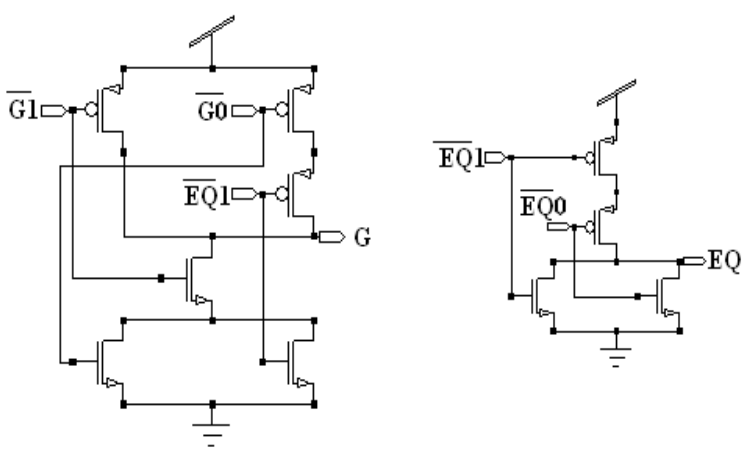

Figure 5 Schematic of Stage $2^{\text {nd }}$ of Existing 64-Bit Binary Comparator

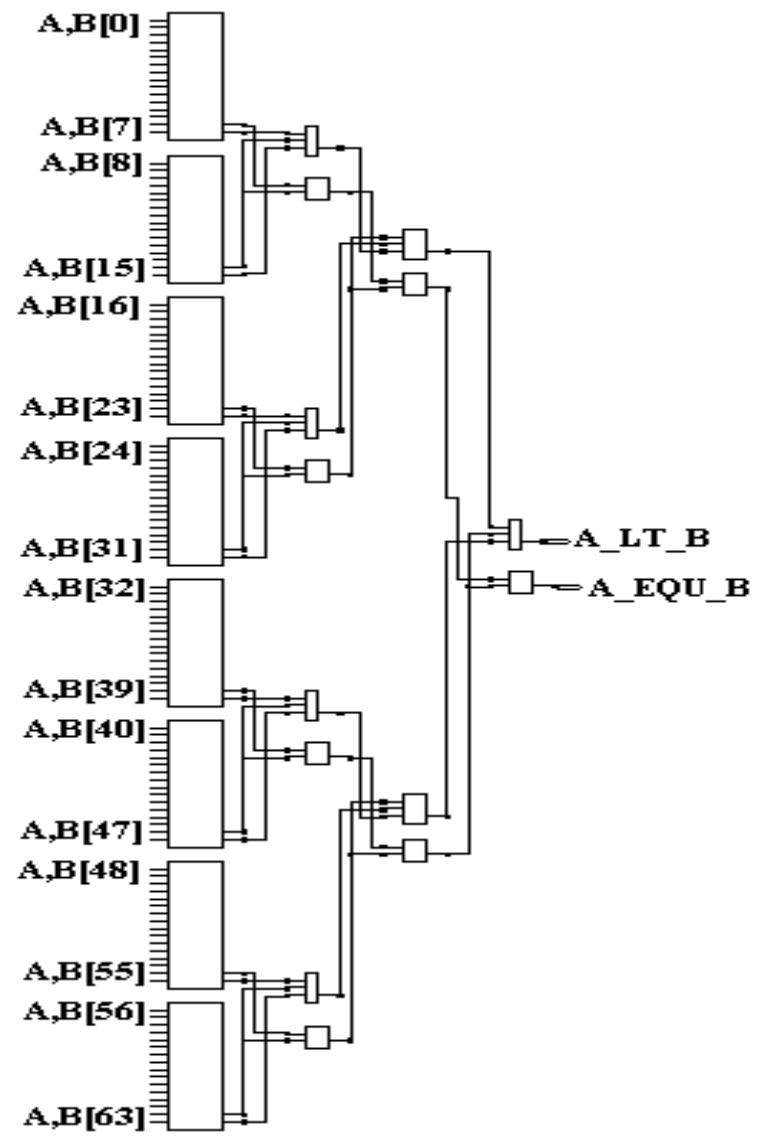

Figure 6 Schematic of Existing 64-Bit Binary Comparator
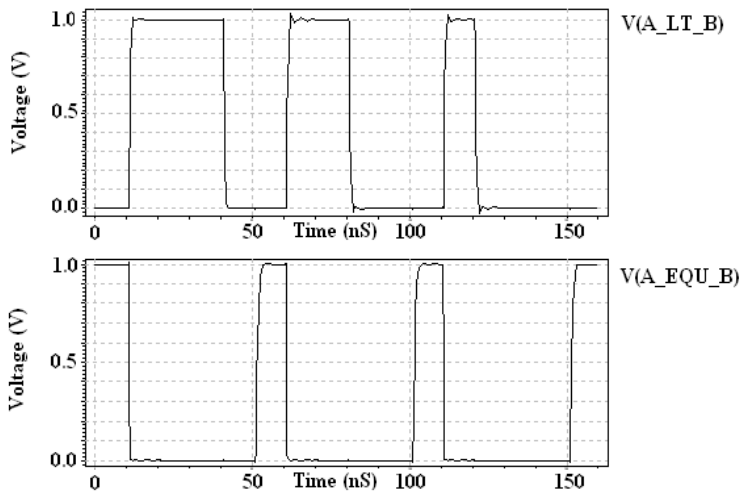

Figure 7. Waveforms of Existing 64-Bit Binary Comparator

According to input bit stream, waveforms of existing 64-bit binary comparator are obtained and shown in Figure 7. Waveforms show that only one output is high (" 1 ") at a time. When both the outputs "less than" \& "equal to" (A_LT_B \& A EQU B) are low ("0"), then waveforms represent that "greater than" output is high (A_GT_B is "1"). Simulation results for this design are given in table III for conclusion. 


\section{MODIFIED 64-BIT BINARY COMPARATOR DESIGN}

Some modifications are done for stage $0^{\text {th }}$ in existing 64-bit comparator design [3] to improve the speed of the circuit.

For this design, all three basic stages are implemented using CMOS logic style. Means stage $0^{\text {th }}$ of comparator is implemented using CMOS logic style (as in Figure 8) that was implemented using modified PTL style in existing design. Remaining two stages $\left(1^{\text {st }} \& 2^{\text {nd }}\right)$ are exactly same as existing 64-bit comparator design (Figure 4 \& 5). Schematic (using instances of each stage) of this modified 64-bit CMOS binary comparator design is same (externally) as existing 64-bit comparator design which is shown in Figure 9. Description of this design is given in tabular form in table II.

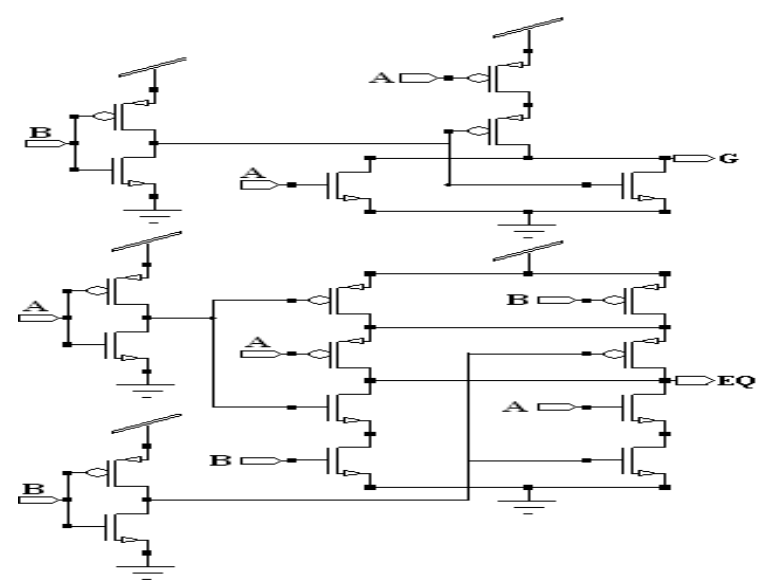

Figure 8 Schematic of Stage $0^{\text {th }}$ of Modified 64-Bit CMOS Binary Comparator

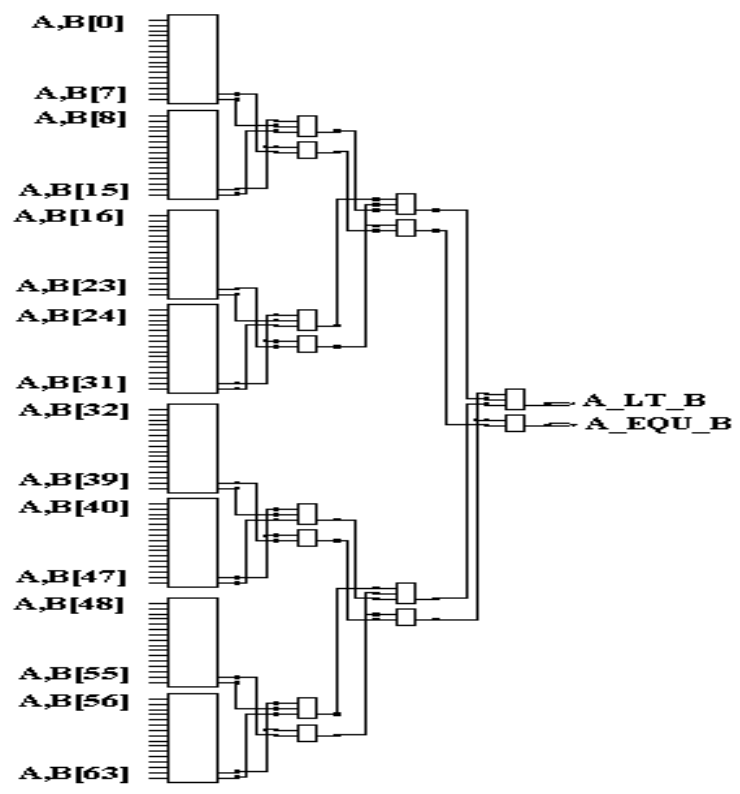

Figure 9 Schematic of Modified 64-Bit CMOS Binary Comparator

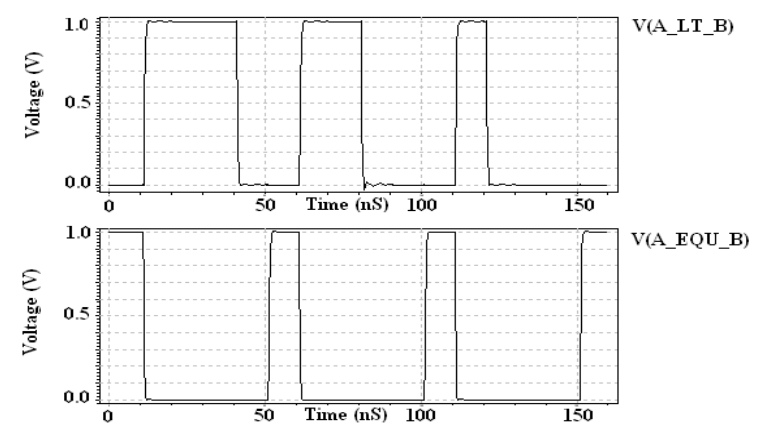

Figure 10 Waveforms of Modified 64-Bit CMOS Binary Comparator

According to input bit stream, waveforms of modified 64-bit CMOS binary comparator are obtained and shown in Figure 10. Input bit stream for this design is same as in existing design of 64-bit comparator. Output waveforms of this design produce same position of $1, \mathrm{~s}$ and $0, \mathrm{~s}$ as in waveforms of existing design for each input bit. Simulation results for this design are given in table III for conclusion.

\section{SIMULATION AND COMPARISON}

After simulation of both the designs final results are obtained for power consumption and delay and are shown in table III. In modified design, delay $\left(\mathrm{t}_{\mathrm{A}_{\perp} \mathrm{LT} \_\mathrm{B}}\right)$ is reduced from $4.4290 \mathrm{e}-$ 009 to $4.4082 \mathrm{e}-009$ means $0.47 \%$ reduction in comparison to existing design and delay $\left(\mathrm{t}_{\mathrm{A}_{-} \mathrm{EQU}} \mathrm{B}\right)$ is reduced from $6.7628 \mathrm{e}-$ 010 to $6.6797 \mathrm{e}-010$ means $1.23 \%$ reduction in comparison to existing design. Graphical representation is in Charts 1 and 2.

\section{CONCLUSIONS}

All of the reduction in delay is obtained after sacrificing power consumption and transistor count. But still modified design gives better result (for delay) than existing 64-bit binary comparator design. In modified design, delay $\left(\mathrm{t}_{\mathrm{A}_{-} \mathrm{LT}_{-} \mathrm{B}}\right)$ is reduced $0.47 \%$ and delay $\left(\mathrm{t}_{\mathrm{A}_{-} \mathrm{EQU}} \mathrm{B}\right)$ is reduced $1.23 \%$ in comparison to existing design. Therefore, modified 64-bit binary comparator design can be better option for high-speed applications.

Table I Description of Existing 64-Bit Binary Comparator design

\begin{tabular}{|c|c|c|c|c|}
\hline Detail & $\begin{array}{c}\text { Stage } \\
\mathbf{0}^{\text {th }}\end{array}$ & $\begin{array}{c}\text { Stage } \\
\mathbf{1}^{\text {st }}\end{array}$ & $\begin{array}{c}\text { Stage } \\
\mathbf{2}^{\text {nd }}\end{array}$ & $\begin{array}{c}\text { Transistor } \\
\text { Count }\end{array}$ \\
\hline \multirow{2}{*}{ Design } & $\begin{array}{c}\text { Using } \\
\text { MPTL } \\
\text { Style }\end{array}$ & $\begin{array}{c}\text { Using } \\
\text { CMOS } \\
\text { Style }\end{array}$ & $\begin{array}{c}\text { Using } \\
\text { CMOS } \\
\text { Style }\end{array}$ & \multirow{2}{*}{1206} \\
\cline { 1 - 3 } $\begin{array}{c}\text { Nature of } \\
\text { output }\end{array}$ & Actual & Inverse & Actual & \\
\cline { 1 - 3 }
\end{tabular}


Table II Description of Modified 64-Bit Binary Comparator Design

\begin{tabular}{|c|c|c|c|c|}
\hline Detail & $\begin{array}{c}\text { Stage } \\
\mathbf{0}^{\text {th }}\end{array}$ & $\begin{array}{c}\text { Stage } \\
\mathbf{1}^{\text {st }}\end{array}$ & $\begin{array}{c}\text { Stage } \\
\mathbf{2}^{\text {nd }}\end{array}$ & $\begin{array}{c}\text { Transistor } \\
\text { Count }\end{array}$ \\
\hline Design & $\begin{array}{c}\text { Using } \\
\text { CMOS } \\
\text { Style }\end{array}$ & $\begin{array}{c}\text { Same as } \\
\text { Existing }\end{array}$ & $\begin{array}{c}\text { Same as } \\
\text { Existing }\end{array}$ & \multirow{2}{*}{1782} \\
\cline { 1 - 3 } $\begin{array}{c}\text { Nature of } \\
\text { output }\end{array}$ & Actual & Inverse & Actual & \\
\cline { 1 - 3 }
\end{tabular}

Table III Simulation results for both the designs

\begin{tabular}{|c|c|c|c|}
\hline \multirow{2}{*}{ Designs } & \multirow{2}{*}{$\begin{array}{c}\text { Power } \\
\text { Consumption } \\
\text { (watts) }\end{array}$} & \multicolumn{2}{|c|}{ Delay (seconds) } \\
\hline & & $\mathbf{t}_{\mathbf{A}_{\text {_LT_B }}}$ & $\mathbf{t}_{\mathbf{A}_{\_} E Q U_{-} B}$ \\
\hline Existing & $8.9563 \mathrm{e}-006$ & 4.4290e-009 & $6.7628 \mathrm{e}-010$ \\
\hline Modified & $2.5128 \mathrm{e}-005$ & 4.4082e-009 & $6.6797 \mathrm{e}-010$ \\
\hline
\end{tabular}

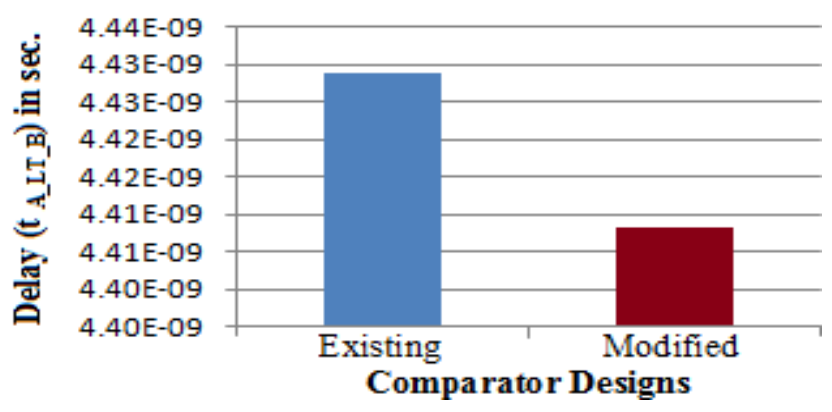

Chart -1: Delay ( $\mathrm{t}_{\text {A_Lt_B }}$ ) vs comparator Designs

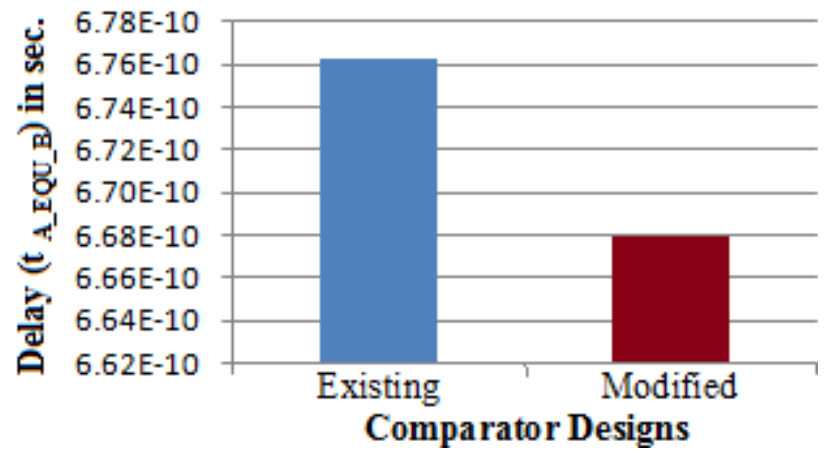

Chart -2: Delay ( $\mathrm{t}_{\text {A_EQU_B }}$ ) vs comparator Designs

\section{ACKNOWLEDGEMENTS}

We are thankful to the Dean, FET and HOD, Department of Electronics \& Communication Engineering for providing us necessary permission to carry out this work.

\section{REFERENCES}

[1] M. Morris Mano "Digital Design" Pearson Education Asia. $3^{\text {rd }} \mathrm{Ed}, 2002$.

[2] A. Bellaouar and Mohamed I. Elmasry, Low Power Digital VLSI Design: Circuits and Systems," Kluwer Academic Publishers, $2^{\text {nd }}$ Ed, 1995.

[3] Pierce Chuang, David Li, and Manoj Sachdev, Fellow, IEEE "A Low-Power High---Performance Single-Cycle Tree-Based 64-Bit Binary Comparator" IEEE Transactions On Circuits and Systems-II: Express Briefs, Vol.59, No. 2,February 2012.

[4] F. Frustaci, S. Perri, M. Lanuzza, and P. Corsonello, "A new low-power high-speed single- clock-cycle binary comparator," in Proc. IEEE Int. Symp. Circuits Syst., 2010, pp.317-320.

[5] S. Perri and P. Corsonello, "Fast low-cost implementation of single-clock-cycle binary comparator," IEEE Trans. Circuits Syst. II, Exp. Briefs, vol. 55, no. 12, pp. 1239-1243, Dec. 2008.

[6] R. Zimmermann and W. Fichtner, "Low Power Logic Styles: CMOS Versus Pass Transistor Logic" IEEE Journal of Solid State Circuits, Vol.32, No.7, pp10791090, July 1997.

[7] S. Kang and Y. Leblebici "CMOS Digital Integrated Circuit, Analysis and Design" Tata McGraw-Hill, $3^{\text {rd }}$ Ed, 2003. 